\title{
PARA ALÉM DA RENDA \\ Uma análise da pobreza multidimensional no Brasil
}

\author{
Murilo Fahel
}

Fundação João Pinheiro (FJP), Belo Horizonte - MG. E-mail: murilo.fahel@fjp.mg.gov.br

\section{Letícia Ribeiro Teles}

Fundação João Pinheiro (FJP), Belo Horizonte - MG. E-mail: leriteles@gmail.com

\section{Davy Alves Caminhas}

Universidade Federal de Minas Gerais (UFMG), Belo Horizonte - MG. E-mail: davycaminhas@gmail.com

DOI: $10.17666 / 319205 / 2016$

\section{Introdução}

A mensuração e a análise da pobreza no Brasil mostram-se cada vez mais relevantes com base nas evidências empíricas da acelerada queda recente da pobreza extrema no país. Em certa medida, isso ocorreu em função das políticas e dos programas sociais de combate à pobreza que se mostraram bem-sucedidos, com relativa sustentabilidade política e econômica e sem risco de descontinuidade. ${ }^{1}$ Novos desafios, além dos objetivos de redução da extrema pobreza, emergiram, como, por exemplo, a promoçấo da mobilidade social e econômica dos estratos da população com baixo nível socioeconômico e a interrupção da reprodução da pobreza intergeracional. Desse modo, a medida unidimensional da pobreza baseada exclusivamente no rendimento mostra-se insuficiente para

Artigo recebido em 28/05/2015

Aprovado em 16/02/2016 captar o universo das necessidades dos mais pobres, que se manifesta por meio de várias dimensóes, como saúde, educação, emprego e condiçôes de habitação. Nessa perspectiva, a configuração da multidimensionalidade da pobreza e suas medidas tomam parte do escopo das políticas sociais no país, com a introdução, concomitante, de uma nova agenda na arena social.

A adoção do conceito de pobreza multidimensional pelo programa Brasil Sem Miséria, como uma estratégia para gerar uma melhor compreensão dos objetivos propostos na área social, reabriu o debate sobre a necessidade de repensar os limites dos programas sociais no combate à pobreza. $\mathrm{O}$ avanço dessa abordagem em níveis nacional e subnacional e sua disseminação exige um maior aprofundamento do conceito de pobreza multidimensional para o (re)desenho e a maximização de resultados dos novos programas sociais em processo de implementação.

Neste artigo propóe-se uma análise inicial dos indicadores sociais e de pobreza no Brasil e na 
América Latina, destacando as transformaçóes relevantes ocorridas a partir dos anos de 1990. Argumenta-se que, no caso do Brasil, essas mudanças ocorrem em um contexto de reestruturação importante do sistema de proteção social.

O artigo também apresenta uma breve revisão do conceito de pobreza multidimensional e sua interação com as políticas públicas fundamentado na teoria do desenvolvimento humano do economista indiano Amartya Sen, bem como examina a metodologia de mensuração da pobreza multidimensional ${ }^{2}$ para o desenvolvimento de uma análise empírica para o caso Brasil. Para isso, adota a metodologia de modelagem do IPM global proposta por Alkire e Foster (2011a, 2011b), utilizando os dados da Pesquisa Nacional por Amostra de Domicílios - PNAD de 2002, 2007, 2012 e 2013. Assim, produz a modelagem do Índice de Pobreza Multidimensional (IPM) do Brasil, incluindo sua desagregação em cinco macrorregióes brasileiras, 27 unidades da federação e também em áreas urbana e rural.

\section{O conceito de pobreza multidimensional}

A questão da pobreza é largamente discutida na literatura, mas seu reconhecimento como um fenômeno multidimensional mostra-se contra-hegemônico e inovador. A mensuração multidimensional expande o escopo de análise da pobreza e constitui uma alternativa avançada de explicação do fenômeno pobreza.

No Brasil, a metodologia para mensuração da pobreza mais utilizada é a de insuficiência calórica, seguida de metodologias que consideram alguma linha de pobreza definida em termos monetários, que são, portanto, de caráter unidimensional. Existem também linhas de pobreza subjetivas e relativas, mais comumente utilizadas em países europeus da OCDE, e ainda a supracitada abordagem multidimensional da pobreza, já amplamente adotada na América Latina, mas, ainda, não muito difundida no Brasil.

A análise de Sen (2000), respaldada no conceito de pobreza multidimensional, introduz parâmetros fundados nos princípios da justiça social juntamente com a criação de um novo conceito de bem-estar, considerando a pobreza um fenômeno não mais restrito a meios e recursos que os indivíduos possuem, mas que abrange sua liberdade de escolha em relação à sua proposição de vida. $\mathrm{O}$ foco de Sen sobre a pobreza é baseado em dois conceitos inter-relacionados: i) funcionamentos referentes aos estados e às ações que os indivíduos desejam viver; ii) capacidade, que se refere à possibilidade de a pessoa estar capacitada para exercer sua liberdade de escolha em relação aos diferentes caminhos possíveis.

Dessa maneira, os funcionamentos relevantes podem variar desde algo elementar, como ser adequadamente nutrido, possuir bom estado saúde, estar livre de doenças previsíveis e com uma ameaça reduzida de morte prematura, até realizaçóes mais complexas, como ser feliz, ter autorrespeito e sentir-se como parte da vida em comunidade. Intimamente relacionada com o conceito de funcionamento é a ideia de autonomia, ou seja, a capacidade para trilhar caminhos e tomar decisóes. Isso representa as várias combinaçôes de funcionamentos (estados e açóes) que uma pessoa pode realizar. A capacidade é, portanto, um conjunto de vetores de funcionamentos que refletem a liberdade pessoal para escolher um estilo de vida ou outro. Assim, a perspectiva de uma abordagem multidimensional é inovadora para a compreensão do fenômeno da pobreza, contribuindo para a superação dos dilemas consensuais inerentes à sua concepção e complexidade no processo de mensuração. Em contrapartida, esse novo conceito passa a exigir formas inovadoras de intervenção das políticas sociais. Uma questão importante a ser explorada é qual seria a melhor escolha para fazer diante da pobreza, considerando-se que a estratégia de mensuração é um modo interdependente de intervenção e requer a diversificação de políticas e programas para ampliar seu impacto.

\section{Pobreza multidimensional e políticas públicas}

Importante considerar que a amplitude e a elasticidade da perspectiva multidimensional da pobreza exigem um novo escopo das políticas pú- 
blicas. Assim, a ancoragem de suas premissas no binômio escolha-oportunidade como dimensão fundante das capacidades e dos atributos dos indivíduos induz a uma reconfiguração das políticas públicas, com especial atenção para as políticas marcadamente de cunho social. Em outras palavras, há uma demanda vinculante à sua efetividade de que as políticas públicas/sociais incorporem as múltiplas dimensóes do desenvolvimento: econômico, social, político, ambiental e cultural para proporcionar aos indivíduos uma condição de bem-estar pleno e sustentável.

A análise da pobreza em uma visão multidimensional, contextualizada e personalizada examinando aspectos constituintes de cada sociedade e/ou comunidade, com um alcance de suas múltiplas dimensóes estruturantes, pode proporcionar uma matriz abrangente para o direcionamento de propósitos e metas das políticas públicas sociais. Cabe, então, pensar no papel estratégico da transição de um conceito unidimensional da pobreza e eminentemente economicista, ainda adotado por diversos organismos multilaterais e governos, para uma perspectiva multidimensional e focalizada nas dimensôes sociais estruturantes da vida humana. Ou seja, em última instância, a simples configuração de um diagnóstico multidimensional da pobreza pode contribuir de maneira relevante para o (re)desenho e os propósitos das políticas públicas/sociais, gerando uma transformação estrutural em seu escopo e abrangência, bem como alterando significativamente sua concepção de efetividade. Assim, há uma intencionalidade latente com essa nova conceituação da pobreza: a geração de impacto no processo de descanonizaçáo das políticas públicas/sociais para a emergência de pressupostos calcados na ética do desenvolvimento humano e sustentável.

É possível identificar essa evolução do pensamento social-institucional a partir da década de 1990 por meio do Relatório de Desenvolvimento Humano do PNUD, que desloca o foco de análise da pobreza para o enfoque do desenvolvimento humano. $\mathrm{Na}$ visão do PNUD, desenvolvimento humano caracteriza-se pelo processo de expansão das escolhas individuais. Nessa perspectiva, se o desenvolvimento humano significa a ampliação das escolhas, na pobreza há uma negação de oportunidades mais básicas, interferindo no atingimento de uma vida longa, saudável e criativa (PNUD, 1997). Nota-se que esse novo paradigma de concepção da pobreza vem expandindo sua aceitação no mundo junto com o uso dos parâmetros conceituais e mensuráveis da pobreza multidimensional e, também, vem influenciando cada vez mais o desenho e a implementação das políticas públicas sociais. Em especial, no Brasil e no contexto da América Latina, observa-se a manifestação dessas tendências, principalmente por meio da reconfiguração de seus sistemas de proteção social.

\section{As mudanças relevantes no sistema de proteçáo social no Brasil}

Após a Constituição de 1988, o Brasil adotou um novo paradigma de políticas sociais fundadas nos direitos sociais, o que significou uma mudança radical em relação à visão tradicional de assistência social utilizada até então e levou à implementação de vários programas sociais inovadores. Quase três décadas mais tarde, foi observada uma importante redução da pobreza com impacto positivo sobre as desigualdades sociais. Claro, esses resultados estão também associados à estabilidade da inflação, alcançada em meados da década de 1990, e ao crescimento econômico que tem ocorrido, sobretudo, na última década.

Desde então, o sistema de proteção social no Brasil apresenta uma expansão da sua cobertura para a população vulnerável por meio da criação de políticas e programas que promovem uma maior inclusão social no país. No entanto, os critérios para mensuração da pobreza eram tradicionalmente restritivos, por levarem em conta táo somente aspectos econômicos e não adotarem uma abordagem mais abrangente.

A partir de 2011, o governo brasileiro adota, através do programa Brasil Sem Miséria, o princípio da pobreza multidimensional, reconfigurando seus critérios de elegibilidade e seu portfólio de programas sociais e propondo novos desafios para a concepção e a implementação de políticas sociais no país. A partir daí assistimos a uma proposição de maior aplicação e disseminação do Índice de Pobreza Multidimensional (IPM). 
Figura 1

Evolução da Proporçáo de Pessoas Pobres (\%) e Indigentes na América Latina, 1990-2013*

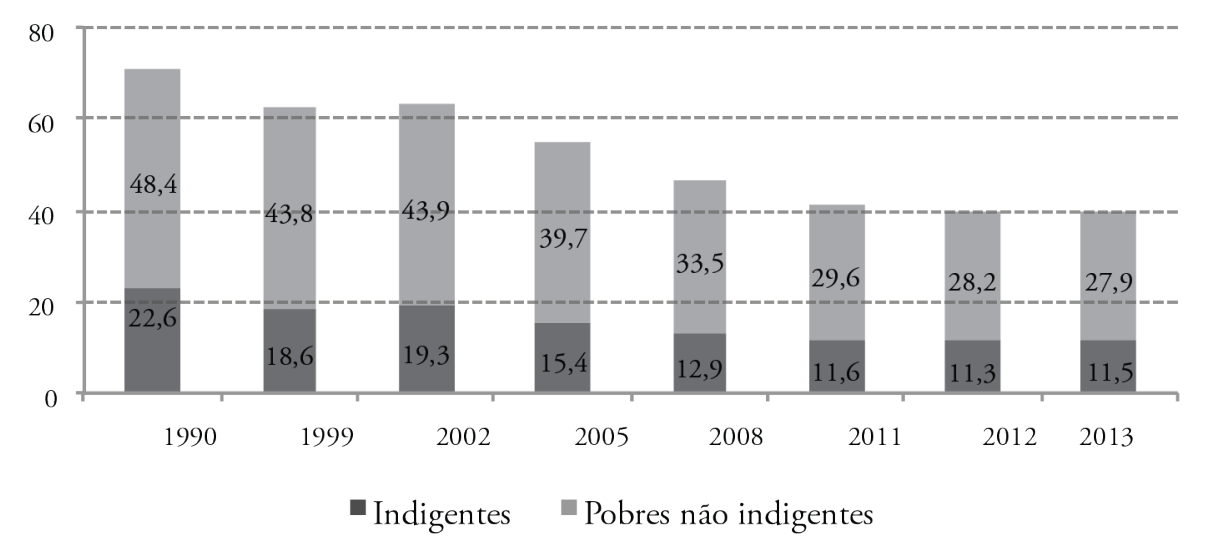

* Estimativa correspondente a dezoito países da região, mais Haiti. As cifras que aparecem sobre as seções superiores das barras representam a porcentagem de pessoas pobres (indigentes e pobres não indigentes). As cifras de 2013 correspondem a uma projeção.

Fonte: Comissão Econômica para a América Latina e o Caribe (Cepal), com base em tabulaçóes especiais das pesquisas de domicílios dos respectivos países.

\section{Pobreza no Brasil e na América Latina}

De acordo com a Comissão Econômica para a América Latina e o Caribe - Cepal (2013), a incidência de pobreza monetária na América Latina apresenta uma tendência declinante, embora em ritmo inferior ao desejado. Em 2013, 27,9\% (164 milhóes) da população latino-americana era considerada pobre e 11,5\% (66 milhóes), extremamente pobre ou indigente (Figura 1).

$\mathrm{Na}$ última década, a pobreza na América Latina apresenta uma redução de maneira generalizada, com uma queda expressiva de dezesseis pontos percentuais desde 2002, enquanto a extrema pobreza mostra uma tendência de queda menos acentuada. Por sua vez, tanto o número de indigentes quanto o de pobres não indigentes tiveram uma desaceleração em seu ritmo de queda, principalmente nos últimos cinco anos.

Para além da mensuração da pobreza monetária, hoje já se adota uma abordagem multidimensional da pobreza na América Latina, também baseada na metodologia proposta Alkire e Foster (2009), mas que possui, ainda, um caráter essen- cialmente exploratório. Para essa análise empírica são considerados os indicadores tradicionais de necessidades básicas insatisfeitas: padrão de vida (água, saneamento, eletricidade, combustível para cozinhar, materiais da moradia e amontoamento) e educação (anos de escolaridade e frequência escolar). São considerados pobres todos aqueles privados em ao menos dois dos oito indicadores considerados. Na Figura 2, temos os dois índices calculados, expressando a incidência de pobreza ou proporção de pobres $(\mathrm{H})$ e a intensidade da pobreza (A), a qual representa o percentual médio de privaçóes experimentadas pelos pobres. ${ }^{3}$

Vale notar que a incidência e a intensidade da pobreza apresentam uma relação positiva, indicando que os países com maior proporção de pobres são também aqueles nos quais os pobres são acometidos por maior número de privação.

O Brasil, a despeito de ser bem posicionado quanto à renda na comparação com o restante do mundo (cerca de $80 \%$ dos países têm uma renda per capita mais baixa que a do Brasil), tem um elevado nível de pobreza devido à forte desigualdade na distribuição de renda. Entretanto, observa-se 
Figura 2

América Latina (17 países) - Incidência (H) e Intensidade (A) da Pobreza, 2011*

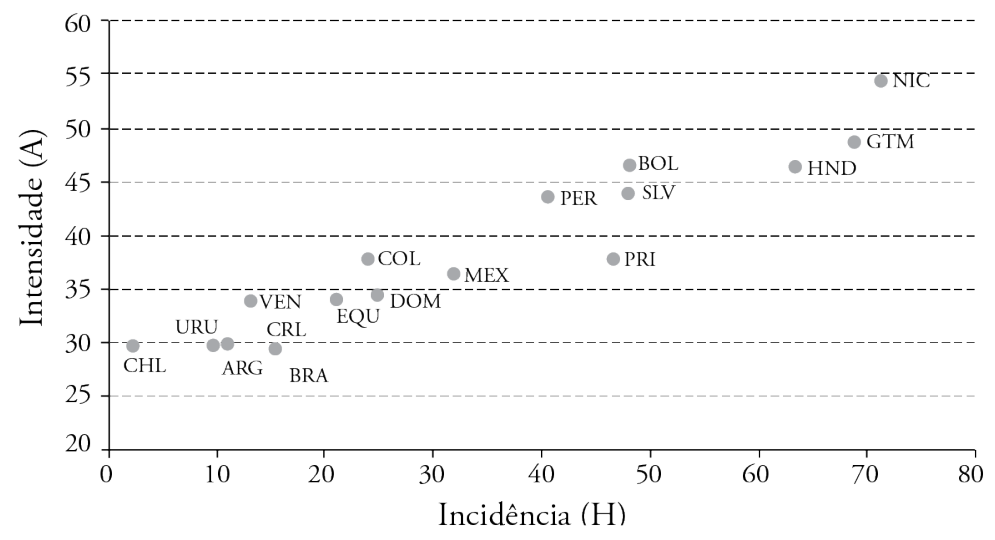

* Os dados correspondem a 2011, exceto no caso da Bolívia (2009), El Salvador (2010), Guatemala (2010), Honduras (2010), México (2010) e Nicarágua (2009). Os dados da Argentina correspondem às áreas urbanas.

Fonte: Comissão Econômica para a América Latina e o Caribe (Cepal), com base em tabulaçóes especiais das pesquisas de domicílios dos respectivos países.

uma tendência de reduçáo da pobreza e da pobreza extrema nos últimos anos. Por conseguinte, fica evidente que o Brasil não é um país pobre, mas enfrenta o desafio histórico de lidar com o mal-estar da injustiça social com exclusão de uma parcela significativa de sua população, que tem acesso apenas às condiçóes mínimas de vida. As áreas mais pobres são as regiōes Norte e Nordeste; as mais ricas, Sul e Sudeste, que abrangem cerca de $45 \%$ da populaçáo com o menor percentual de pessoas pobres.

Como o exposto pelo Ipea em seu comunicado de 2012 sobre a "década inclusiva" (20012011), a desigualdade de renda do Brasil está entre as quinze maiores do mundo apesar de ter atingido, no fim da década de $2000,{ }^{4}$ o piso da série histórica do índice de Gini iniciada em 1960. Com o fim da recessão, a partir de 2003 o Brasil voltou a crescer e até 2011 registrou uma taxa acumulada de crescimento, segundo a PNAD, de $40,7 \%,{ }^{5}$ contribuindo fortemente para reduzir a situação de pobreza no país. É importante ressaltar que, na chamada "década inclusiva", a renda dos $10 \%$ mais pobres cresceu $550 \%$ mais rápido que a dos $10 \%$ mais ricos, o que configura de fato uma situação de expressiva redução da desigualdade de renda.

Observa-se, entáo, que a queda da pobreza foi proporcionada pelo crescimento econômico concomitante a uma forte queda da desigualdade. Ainda de acordo com o Ipea (2012), a redução recente da desigualdade, por sua vez, teve como principais causas $^{6}$ (1) expansão trabalhista que ocorreu via aumento do trabalho formal e queda na taxa de desemprego, conferindo estabilidade ao processo e (2) as políticas redistributivas do governo, configurando uma situação de crescimento inclusivo. Assim, com crescimento aliado a uma menor desigualdade, a pobreza foi inequivocamente reduzida, independentemente do critério de mensuração. A pobreza extrema está agora situada em um patamar abaixo do proposto pelos Objetivos do Desenvolvimento do Milênio da ONU.

\section{Indicadores sociais no Brasil e na América Latina}

Com uma análise longitudinal, verificou-se que tanto o Brasil quanto a América Latina apre- 
sentam uma evolução positiva de seus indicadores sociais (Figura 3). No Brasil, a média de anos de escolaridade aumentou muito em função do processo de universalização do acesso à educação básica, que vem ocorrendo desde 1994. Esse progresso ainda não é o suficiente, mas é importante frisar que a situação da educação brasileira passa por uma transformação consistente.

A América Latina comporta países com realidades bastante distintas, mas observa-se que o nível educacional da regiáo, em termos de anos de escolaridade, é em média superior ao do Brasil. A taxa de mortalidade infantil apresenta também uma tendência claramente declinante, mas ainda se encontra acima do padrão internacional recomendado pela Organização Mundial da Saúde (OMS). O acesso ao saneamento básico tem sido muito semelhante entre as regióes, apresentando tendência de progresso contínuo. A taxa de desemprego, regularmente, flutua mais por sua associação estrita com a conjuntura econômica, mas no Brasil e na América Latina a tendência, a partir de 2002, vem sendo de reduçáo e estabilidade. No Brasil, ocorreu uma expansão trabalhista recente, ampliando o emprego formal e fazendo crescer a renda do trabalho.

Figura 3

Evoluçáo dos Indicadores Sociais no Brasil e na América Latina

Anos de Escolaridade

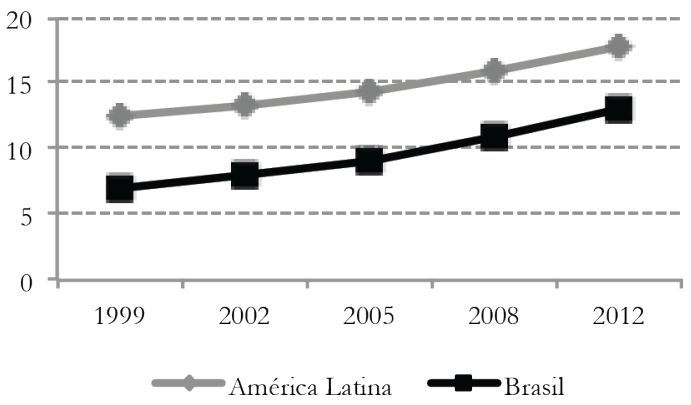

Saneamento Básico

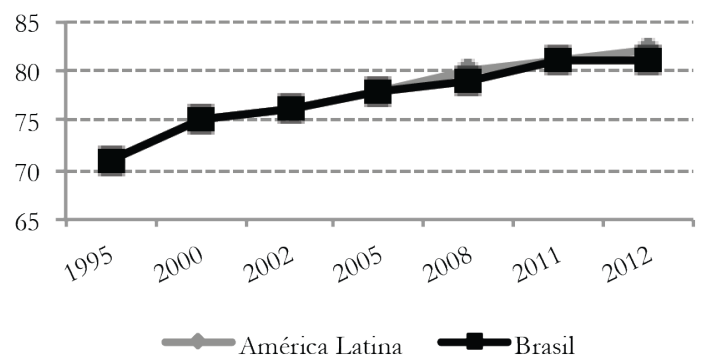

Mortalidade Infantil

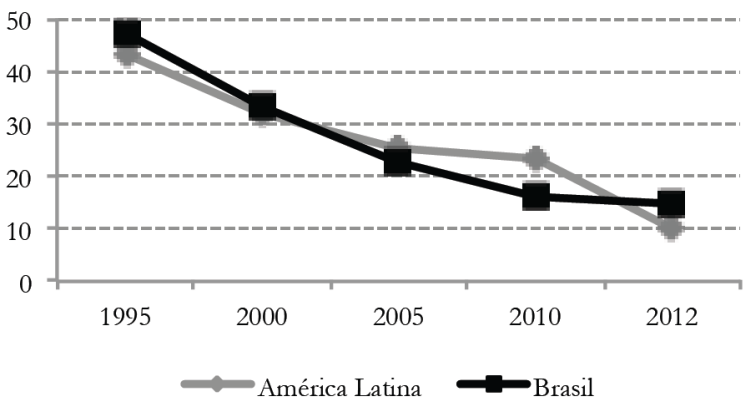

Taxa de Desemprego

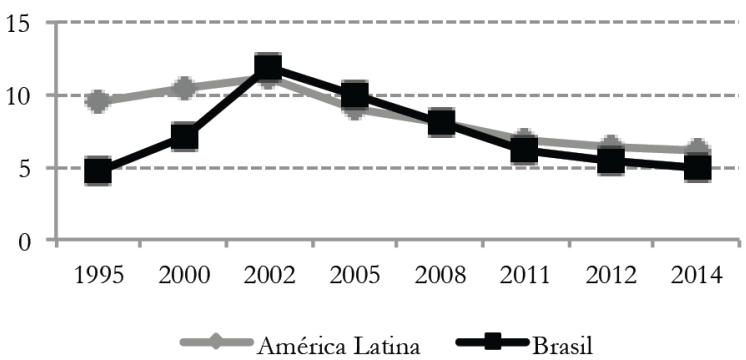

*Taxa de mortalidade por 1.000 nascimentos para crianças de até 5 anos de idade; **Proporção da população com acesso ao abastecimento de água tratada, exclusive serviço de coleta de esgotos sanitários e coleta de lixo. Dados preliminares para 2014; ${ }^{* * *}$ Taxa média anual.

Fonte: Elaboração própria com dados da Cepal (Anos de Escolaridade e Taxa de Desemprego), IGME (Mortalidade Infantil) e OMS/Unicef (Saneamento Básico). 


\section{A mensuraçáo da pobreza multidimensional}

Para a realizaçáo dos objetivos propostos foi utilizado o know-how já desenvolvido e aplicado pelo The Oxford Poverty and Human Development Initiative (OPHI) na mensuração do IPM em vários países (inclusive no Brasil), com uso da referida metodologia proposta por Alkire e Foster (2011a e 2011b). Neste estudo o índice foi personalizado, considerando as especificidades socioeconômicas do país.

\section{O corte da linha da pobreza (identificação do pobre pelo IPM)}

A cada pessoa é atribuída uma pontuaçáo de privaçấo (de 0 a 1 , ou $0 \%$ a $100 \%$ ) de acordo com suas privaçóes nos indicadores que compóem o índice, calculada a partir da soma ponderada das privaçóes vivenciadas. Em seguida, a pessoa é identificada como multidimensionalmente pobre caso seja privada em $\mathrm{x} \%$ dos indicadores ponderados. A pontuação aumenta à medida que o número de privaçóes cresce e atinge seu máximo de 1 , quando a pessoa é privada em todos os indicadores analisados. Uma pessoa que náo é considerada privada em qualquer indicador recebe uma pontuação igual a 0 . Formalmente:

$$
c_{i}=w_{i} I_{1}+w_{2} I_{2}+\ldots+w_{d} I_{d}(1) \text { onde } I_{1}=1 \text {, se }
$$
o domićlío é privado no indicador $i$, e $I_{i}=0$, caso contrário, e $w_{i}$ é o peso atribuído ao indicador $i$ $\operatorname{com} \sum_{i=1}^{d} w_{1}=1 .^{8}$

O segundo corte é utilizado para identificar o multidimensionalmente pobre, o que na metodologia de Alkire-Foster é chamado de corte da pobreza. Trata-se da proporção (ponderada) de privaçôes que o domicílio deve ter para ser considerado pobre, e será denotado por $k$. Alguém é considerado pobre se sua pontuação de privação é igual ou maior que o corte da pobreza, isto é, se $c_{i} \geq k$. No IPM global, uma pessoa é identificada como pobre se tem uma pontuação de privação superior ou igual a 1/3. Em outras palavras, a privação vivenciada por uma pessoa deve ser um terço, pelo menos, dos indicadores (ponderados) para que ela seja considerada pobre pelo IPM. ${ }^{9}$ Para aqueles cuja pontuaçáo de privação está abaixo do ponto de corte da pobreza, mesmo que seja diferente de zero, a sua pontuaçấo é substituída por um ' 0 ' e quaisquer privaçôes existentes não são consideradas nos "headcounts censurados". Referimo-nos a este importante passo da metodologia como censurar as privaçóes dos não pobres; ${ }^{10}$ para diferenciar a pontuação de privação original da pontuaçấo censurada, utiliza-se a notação $c_{i}(k)$ para o escore privação censurada. Nota-se que quando $c_{i} \geq k$, então $c_{i}(k)=c_{i}$, mas se $c_{i}<$ $k$,entấo $c_{i}(k)=0 . c_{i}(k)$ é a pontuação de privação dos pobres.

\section{Calculando o IPM (agregação)}

Seguindo a estrutura da mensuração do Headcount Ajustado $\left(M_{0}\right)^{11}$, o IPM combina duas peças-chave de informaçãa: (1) a proporção ou a incidência de pessoas (dentro de uma determinada populaçáo), cuja participação ponderada de privaçôes é $k$ ou mais, e (2) a intensidade dessa privação, que é a proporção média (ponderada) de privaçóes vivenciadas. Formalmente, o primeiro componente é chamado "índice de incidência multidimensional $(H)$ ":

$$
H=\frac{q}{n}(2)
$$

Neste índice, $q$ é o número de pessoas que são multidimensionalmente pobres e $n$ é a população total. O segundo componente é chamado "intensidade (ou profundidade) da pobreza $(A)$ ). Trata-se da pontuação média de privação das pessoas já consideradas multidimensionalmente pobres, podendo ser expressa como:

$$
A=\frac{\sum_{i=1}^{n} c_{i}(k)}{q}(3)
$$

onde $c_{i}(k)$ é a pontuação de privação censurada do indivíduo $i$ e $q$ é o número de pessoas que são multidimensionalmente pobres. ${ }^{12} \mathrm{O}$ IPM é o produto de ambos:

$$
M_{0}(I P M)=\mathrm{H} \times \mathrm{A}(4)
$$

Outra propriedade interessante desse método é a possibilidade de decomposição dos índices cal- 
culados da seguinte maneira: dado que a pobreza é avaliada para cada indivíduo separadamente e, em seguida, acontece a agregação, é possível desagregar o índice por localização. Além disso, pode-se desagregá-lo por áreas geográficas - estados, regióes, urbano/rural etc. -, bem como é possível avaliar quantas pessoas são privadas em algum atributo específico. Assim como explanado por Alkire e Santos (2010), "a metodologia de Alkire e Foster não especifica dimensões, indicadores, runs, pesos ou cortes, mas é flexível e pode ser adaptada a contextos variados. O IPM global, em contraste, tem dimensóes, indicadores, pesos e cortes específicos" (2010, p. 11, tradução livre dos autores).

\section{Dimensóes e indicadores}

O IPM é baseado na concepção de pobreza segundo Amartya Sem (2000), que considera a pobreza como um fenômeno multidimensional que afeta as pessoas de diversas maneiras. Tal é a razão pela qual a mensuração da pobreza inclui diferentes tipos de privação. Dessa forma, o IPM global mede o fenômeno da pobreza a partir de três dimensões - educação, saúde e padrão de vida - e dez indicadores compreendidos em uma dessas três dimensóes (Figura 4). As dimensóes têm todas o mesmo peso (1/3) e os indicadores de uma dada dimensão são também igualmente ponderados. Em outras palavras, esse índice apresenta uma capacidade analítica que reflete as privaçóes dos indivíduos referentes a serviços elementares e necessidades humanas básicas (Alkire e Santos, 2010).

$\mathrm{O}$ interessante dessa metodologia é sua flexibilidade e capacidade de adaptação a diferentes contextos culturais. Por exemplo, México, Colômbia, Butão e Filipinas adotaram medidas oficiais de pobreza multidimensional e em cada um desses países o índice foi adaptado ao contexto cultural e político nacional. O IPM também proporciona uma análise sob a perspectiva comparada, podendo ser desagregado em diferentes regióes e decomposto de acordo com a contribuiçáo de cada indicador, de maneira que possibilite a identificaçáo de onde e por que a pobreza é mais incidente ou severa. Ademais, o índice é obtido por um método estatístico simples e consistente, além de apresentar outras características desejáveis em um índice de pobreza.

\section{Base de dados e variáveis}

Os dados utilizados para a modelagem do IPM são oriundos da Pesquisa Nacional por Amostra de

\section{Figura 4 \\ Dimensóes, Indicadores e Pesos do IPM para o Brasil}

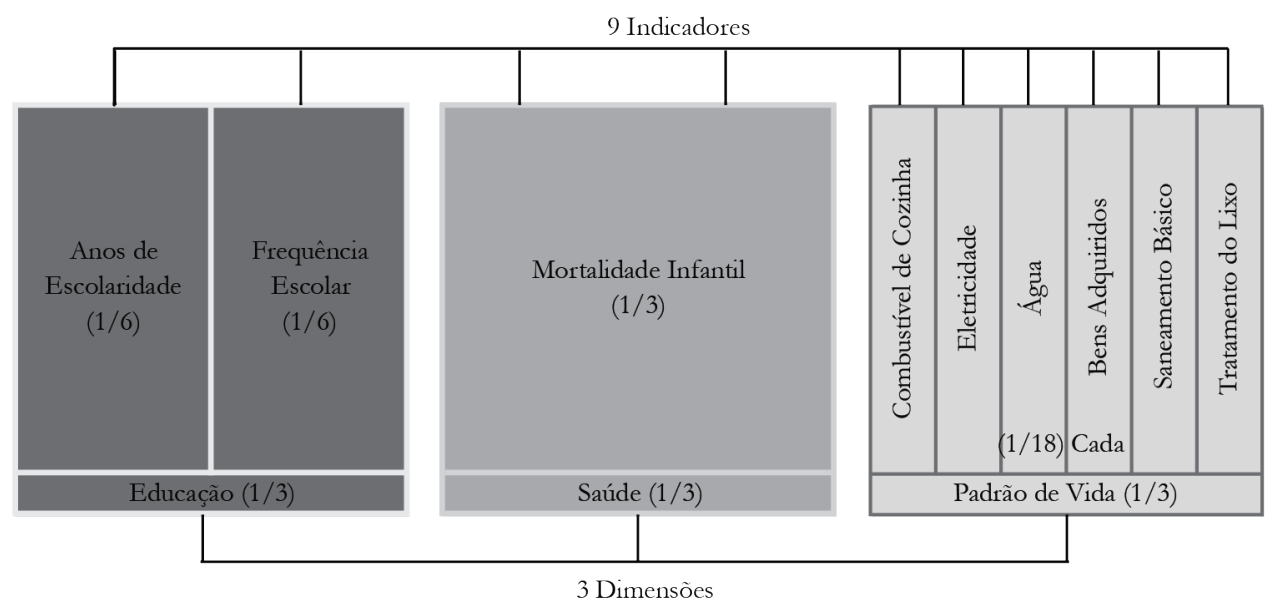

Fonte: Elaboração própria baseada em Santos e Alkire (2011). 
Domicílios (PNAD) realizada pelo IBGE no território brasileiro em 2002, 2007, 2012 e 2013. A produção dessa informação é essencial para o estudo da realidade socioeconômica do país. Conhecendo em profundidade as características e o comportamento da população, o desenvolvimento, o monitoramento e a avaliação de políticas sociais são mais eficientes.

A amostra da pesquisa é composta por aproximadamente 150 mil domicílios em 1.100 municípios brasileiros e coleta informaçóes anuais sobre características demográficas e socioeconômicas da população, como sexo, idade, educação, trabalho e rendimento, e características dos domicílios, e, com periodicidade variável, informaçóes sobre migração, fecundidade, nupcialidade, entre outras.
A definição de dimensões, indicadores, critérios de privação e pesos das variáveis do IPM para o Brasil são semelhantes aos da metodologia proposta por Alkire e Foster (2011a e 2011b). Todavia, no presente estudo, foram realizados alguns ajustes visando à adequação do índice às especificidades do padrão de privação da população brasileira e das variáveis disponíveis no banco de dados, (uso de proxies) (Tabela 1 )

O IPM operacionaliza e simplifica uma análise multifacetada da pobreza, uma vez que um domicílio é considerado pobre se o seu conjunto de privaçóes é equivalente ou superior a 33\% do total. A sistematização, o processamento e a análise de dados para a escolha das dimensóes e dos indi-

Tabela 1

\section{Dimensóes, Indicadores, Critérios de Privaçáo e Pesos}

\begin{tabular}{|c|c|c|c|}
\hline Dimensão & Indicador & Quem é privado? & Peso \\
\hline \multirow[t]{2}{*}{ Educação } & $\begin{array}{l}\text { Anos de } \\
\text { Escolaridade* }^{*}\end{array}$ & $\begin{array}{l}\text { Domicílio no qual nenhum membro com } 16 \text { anos ou } \\
\text { mais tenha completado o ensino fundamental ( } 8 \text { anos de } \\
\text { escolaridade) }\end{array}$ & $16,7 \%$ \\
\hline & Frequência Escolar* & $\begin{array}{l}\text { Domicílio com pelo menos uma criança entre } 6 \text { e } 17 \text { anos que } \\
\text { náo frequenta a escola }\end{array}$ & $16,7 \%$ \\
\hline Saúde & $\begin{array}{l}\text { Mortalidade } \\
\text { Infantil }^{*}\end{array}$ & $\begin{array}{l}\text { Domicílio com pelo menos uma criança até } 5 \text { anos de idade } \\
\text { que tenha falecido }\end{array}$ & $33,3 \%$ \\
\hline \multirow{6}{*}{$\begin{array}{l}\text { Padráo de } \\
\text { vida }\end{array}$} & Eletricidade & Domicílio sem eletricidade & $5,6 \%$ \\
\hline & Água & $\begin{array}{l}\text { Domicílio que não tenha água encanada em pelo menos um } \\
\text { cômodo ou que a água não provenha de cisterna ou nascente. }\end{array}$ & $5,6 \%$ \\
\hline & Saneamento básico* & $\begin{array}{l}\text { Domicílio com sanitário não conectado à rede de coleta de } \\
\text { esgoto (ex. fossa rudimentar) ou o sanitário comunitário } \\
\text { (compartilhado por domicílios). }\end{array}$ & $5,6 \%$ \\
\hline & $\begin{array}{l}\text { Tratamento do } \\
\text { Lixo* }^{*}\end{array}$ & $\begin{array}{l}\text { Domicílio que não tenha tratamento adequado de lixo (por } \\
\text { exemplo lixo queimado ou jogado em rio/lago) }\end{array}$ & $5,6 \%$ \\
\hline & $\begin{array}{l}\text { Combustível de } \\
\text { Cozinha }\end{array}$ & $\begin{array}{l}\text { Domicílio que usa madeira, carvão ou esterco como } \\
\text { combustível de cozinha }\end{array}$ & $5,6 \%$ \\
\hline & Bens Adquiridos* & $\begin{array}{l}\text { Domicílio que tenha três ou menos dos seguintes bens: rádio, } \\
\text { TV, telefone, geladeira, fogão, computador, bicicleta ou moto; } \\
\text { e não tenha carro ou trator }\end{array}$ & $5,6 \%$ \\
\hline
\end{tabular}


Figura 5

Incidência (H), Intensidade (A) e IPM para o Brasil

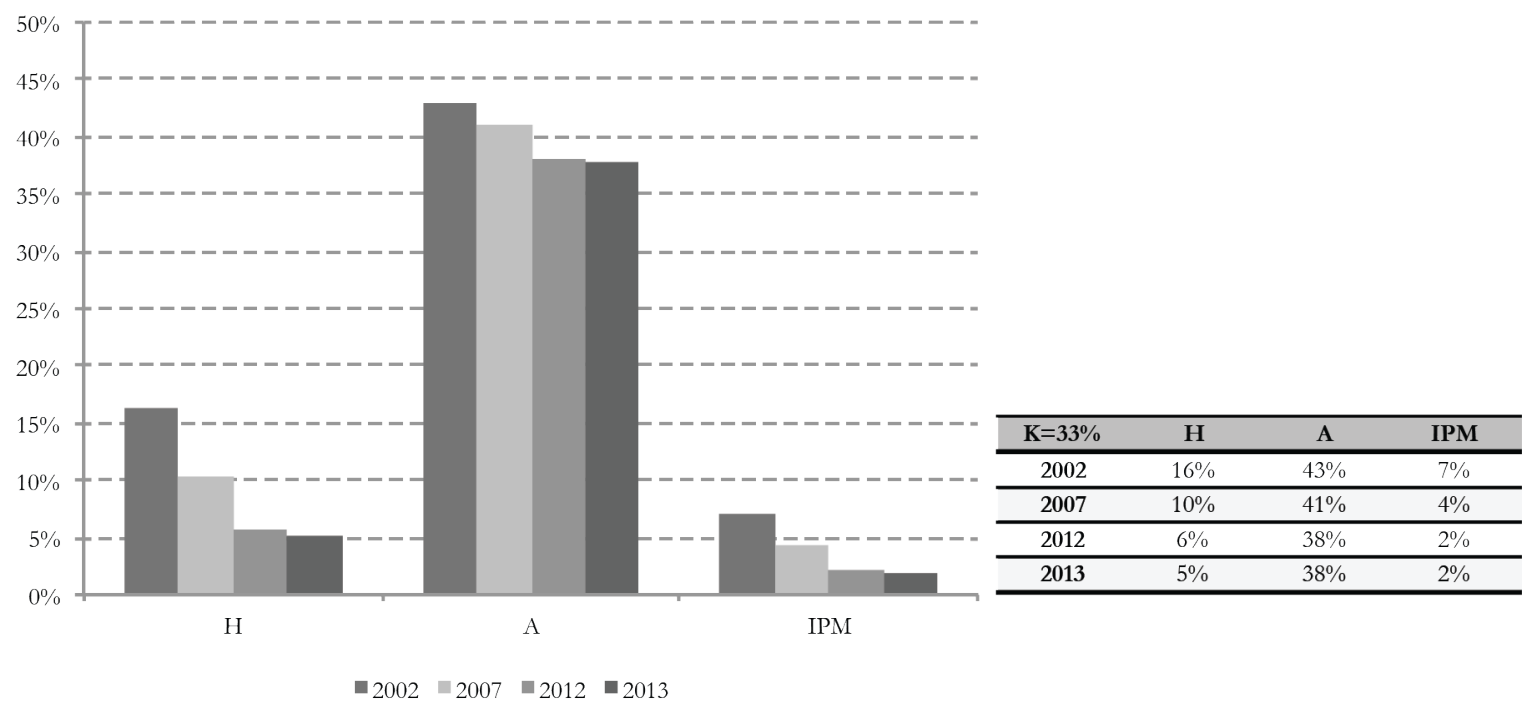

Fonte: PNADs 2002, 2007, 2012 e 2013.

cadores são etapas metodológicas importantes para a calibração adequada do IPM e foram feitas neste estudo utilizando o software estatístico STATA.

\section{Resultados e discussão}

No presente estudo analisa-se o IPM no Brasil desagregando o índice em áreas urbana/rural e pelas cinco macrorregióes do país e 27 unidades da federação. Entre essas diferentes áreas existem consideráveis desigualdades sociais, razão pela qual esta análise pode auxiliar no desenvolvimento de políticas sociais focalizadas.

Os resultados da modelagem indicam que, em 2002, 16\% da população era considerada pobre $(\mathrm{H})$, o que equivale a aproximadamente 27 milhóes ${ }^{13}$ de pessoas. Temos ainda que a intensidade média (A) da pobreza era bastante elevada: aqueles considerados multidimensionalmente pobres eram, em média, privados em 43\% dos indicadores analisados. Para este mesmo ano, o valor do IPM foi de 7\%, que representa a proporção de multidimensionalmente pobres ajusta- da pela intensidade da privação por eles experimentada (Figura 5).

Nota-se que o Brasil apresenta valores expressivos principalmente para a intensidade, mas, também, para incidência de pobreza. No entanto, a tendência de ambos os indicadores é declinante. $\mathrm{Na}$ análise longitudinal, observa-se uma redução expressiva para a incidência da pobreza, com queda de onze pontos percentuais, de modo que, em 2013, a proporção de pobres no Brasil atingiu o patamar próximo de 5\%. Por sua vez, a intensidade apresentou uma variação mais branda, com queda de cinco pontos percentuais, atingindo em 2013 um valor próximo a 38\%. Pela combinação da melhoria, em ambos os indicadores, o IPM no Brasil caiu de 7\% para 2\% entre 2002 e 2013, indicando uma acentuada redução da pobreza multidimensional no país.

Para uma análise desagregada do IPM podese verificar a contribuiçáo que cada dimensão e indicador têm na pobreza da população (Figura 6). A forte reduçáo do índice tem a ver com uma melhoria de todos os indicadores, embora nos quesitos Eletricidade e Bens adquiridos apresen- 


\section{Figura 6}

\section{Contribuiçáo Absoluta e Relativa dos Indicadores para o IPM}

\section{Contribuição absoluta}

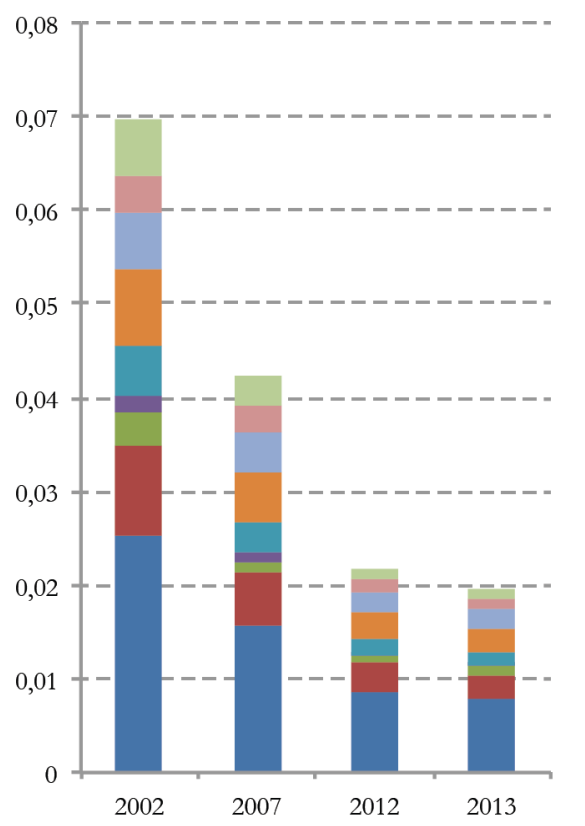

Contribuição relativa

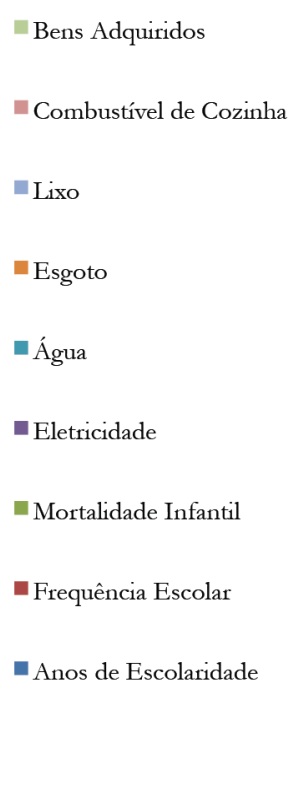

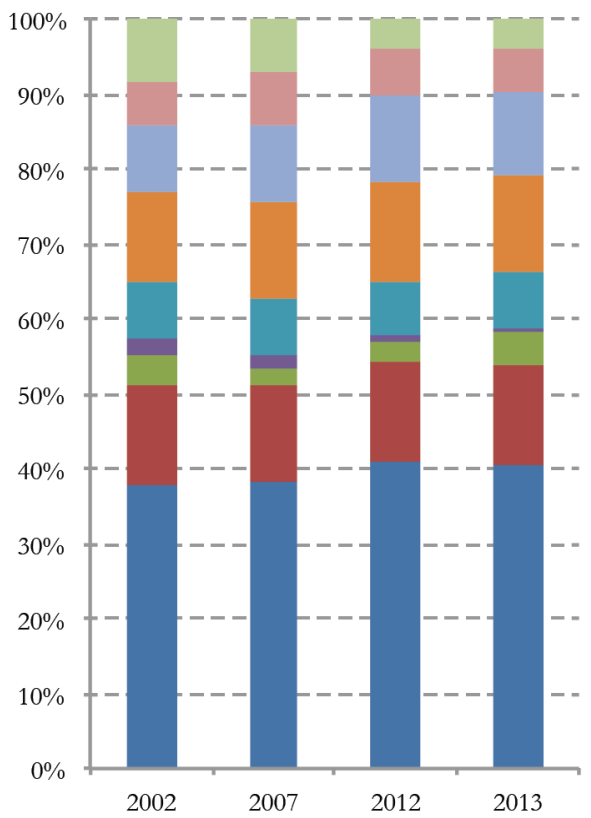

Fonte: PNADs 2002, 2007, 2012, 2013.

tem uma variação proporcionalmente maior, ou seja, houve redução de sua contribuição relativa. Tal resultado é condizente com o que se observa no Brasil recentemente: a diminuição da taxa de desemprego, o aumento real do salário mínimo e o maior acesso ao crédito contribuíram para elevar o consumo de bens duráveis da população de baixa renda, e o programa Luz para Todos ${ }^{14}$ foi um importante determinante para a ampliação do acesso à energia elétrica.

$\mathrm{O}$ indicador de maior contribuição para todo o período da análise é Anos de Escolaridade, com uma contribuição relativa de aproximadamente 40\% para a pobreza multidimensional do Brasil. A agregação de ambos os indicadores referentes à educação (Anos de Escolaridade e Frequência Escolar) corresponde a aproximadamente 50\% do IPM, o que indica sua relevante contribuição relativa na composição da pobreza multidimensional no país e aponta para a necessidade de superar as dificuldades crônicas no campo da educação no país.

A Figura 7 apresenta o índice desagregado por unidades da federação, estando elas agrupadas pelas cinco macrorregiôes brasileiras. Os estados que em 2002 apresentaram os maiores índices de pobreza multidimensional foram todos da macrorregião Nordeste: Piauí (22,4\%), Maranháo (18,81\%) e Alagoas (15,85\%). As localidades que obtiveram os melhores resultados foram São Paulo $(1,25 \%)$, Rio de Janeiro (1,31\%) e Distrito Federal (1,32\%). Em 2013, os três estados com menor IPM são os mesmos de 2002, e os que apresentaram os maiores valores foram Maranhăo, Piauí e, desta vez, o Acre.

Os resultados indicam que desde 2002 tem ocorrido uma reduçâoo sistemática e generalizada da pobreza multidimensional. Entretanto, de 2002 a 2007 a maioria dos estados da macrorregiáo Norte apresentou uma piora do IPM. Já no intervalo de 
Figura 7

IPM por Unidades da Federação

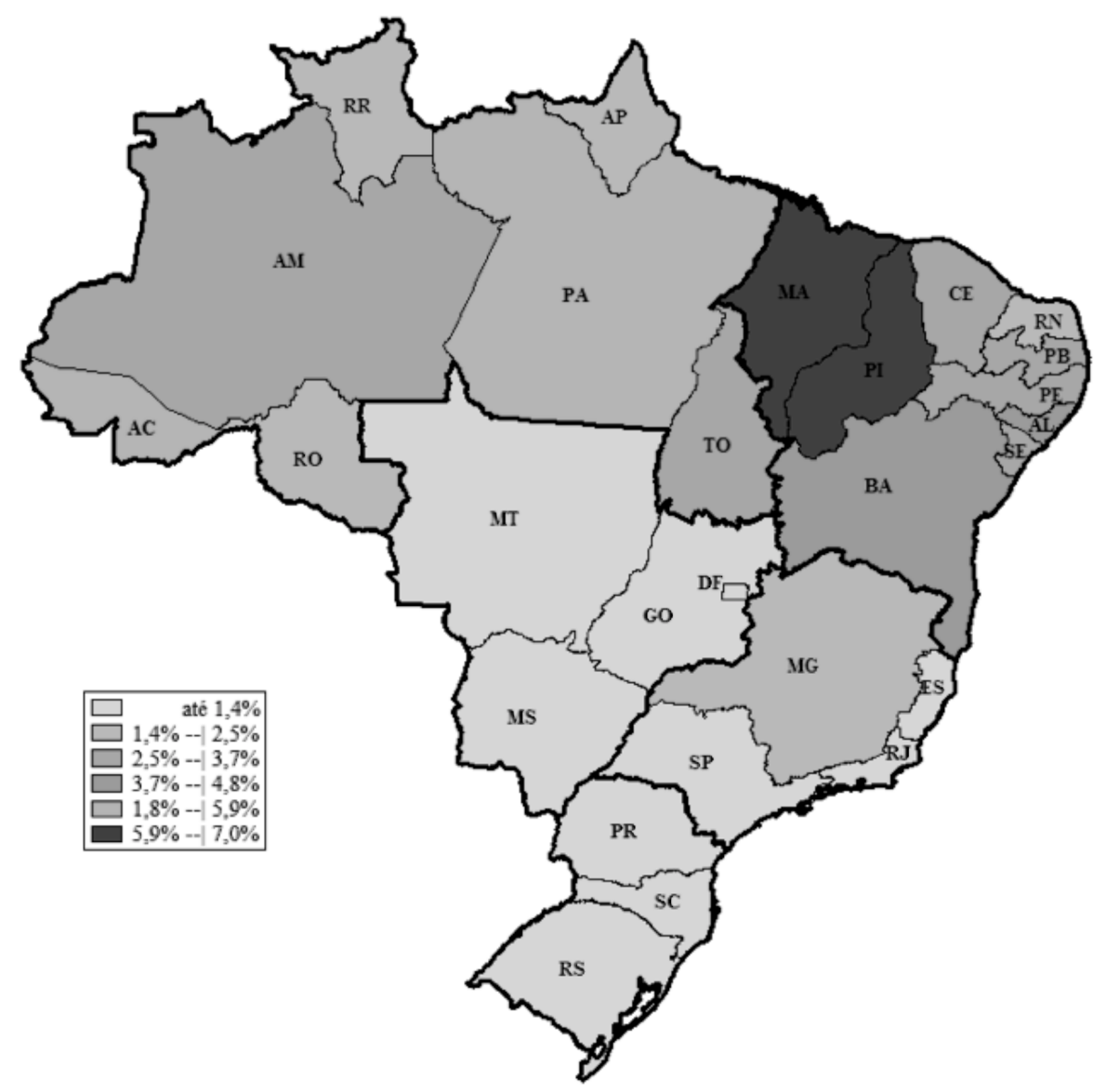

Fonte: PNADs 2002, 2007, 2012, 2013.

tempo entre 2007 e 2012, a diminuição do IPM ocorreu para todos os estados brasileiros, sem exceção. É notável que os estados identificados como os mais pobres em 2002 foram também os que apresentaram uma queda mais pronunciada do IPM. Destaca-se o Nordeste: a redução do índice foi de aproximadamente onze pontos percentuais nesta região e inferior a 4 nas demais. Esse resultado, em alguma medida, pode ser atribuído a uma relativa focalização de políticas do campo da assistência social na região, bem como a investimentos econômicos nas áreas de agricultura e industrial direcionadas para a região na última década.
Os resultados obtidos pela metodologia adotada para mensuração da pobreza multidimensional são semelhantes aos encontrados pela abordagem do Índice de Desenvolvimento Humano (IDH) do Brasil. A visualização espacial desses resultados ( $F i-$ gura 8) destaca o contraste existente no país, dividido entre regióes multidimensionalmente pobres e outras ricas. Sobretudo o Nordeste e o Norte concentram estados onde a pobreza é mais pronunciada. A macrorregião mais bem posicionada é o Sul, seguida do Sudeste e Centro-Oeste.

Em análise concomitante da incidência da pobreza $(\mathrm{H})$, sua intensidade (A) e o IPM (Figura 9), 


\section{Figura 8}

\section{IPM por Unidades da Federação em 2013}

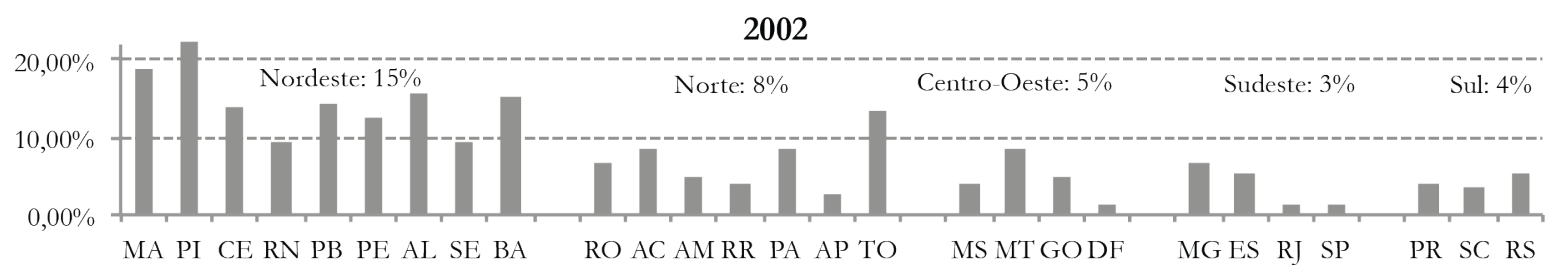

2007

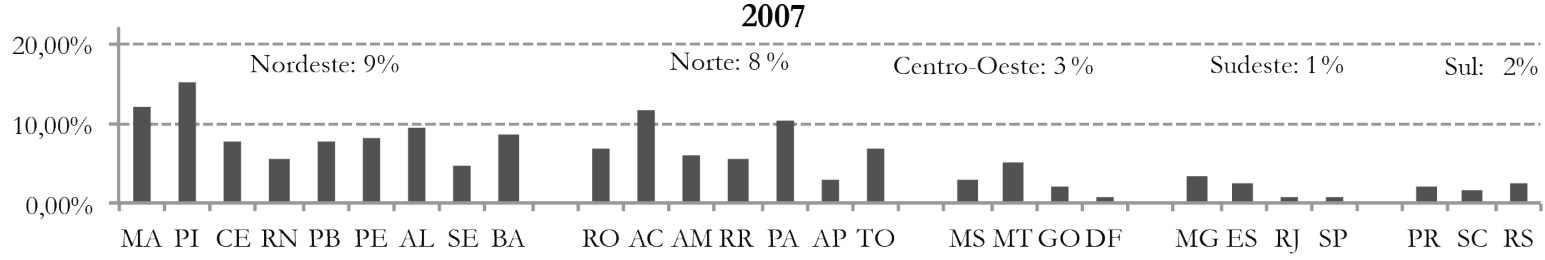

2012

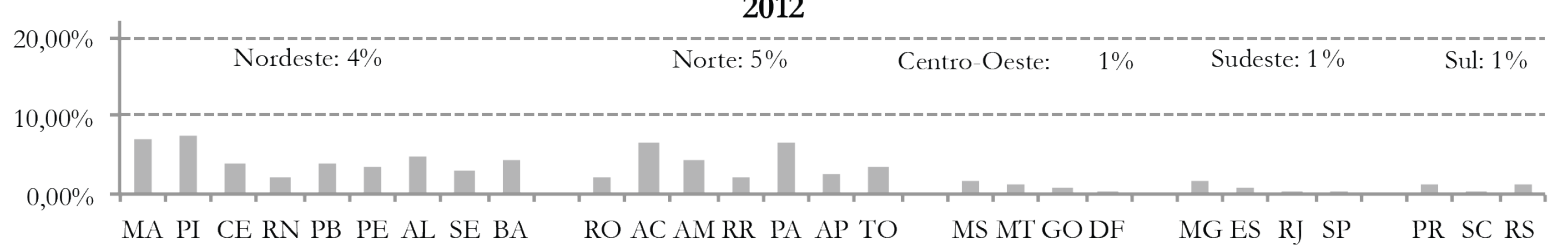

2013

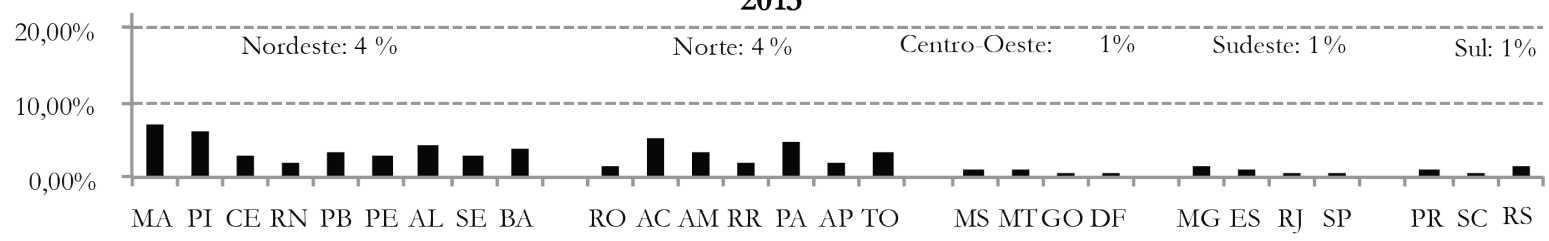

Fonte: Elaboração própria com base na PNAD 2013.

fica evidente o fato de a redução da pobreza multidimensional na transição de 2002 para 2013 ocorre, principalmente, em função da redução na proporção de pobres $(\mathrm{H})$, notadamente mais acentuada do que o observado em relação à intensidade da pobreza (A). Ademais, nota-se que a heterogeneidade entre os estados é maior para o quesito incidência do que para a intensidade, padrão este que se manteve ao longo dos anos considerados.

Observando a relação entre incidência e intensidade da pobreza (Figura 10), observa-se que a redução do IPM foi maior para regióes mais pobres, o que inequivocamente fez diminuir a dispersão entre os estados. O Piauí, estado com maior índice de pobreza no ano de 2002, foi o destaque positivo por ter sido aquele que apresentou maior redução do IPM.

A tendência observada de superação da pobreza extrema depende em certa medida do foco e do curso que as políticas sociais adotam. Como já mencionado, os programas sociais existentes no Brasil em muito contribuíram para esses resultados. Por serem de natureza focalizada e concentrarem-se, portanto, em regióes mais pobres, tais programas exercem um impacto expressivo nas condiçôes de vida da população com efeitos diretos na redução da extrema pobreza.

$\mathrm{Na}$ análise da decomposição do MPI por macrorregiōes (Figura 11), observa-se a contribuição relativa de cada indicador para a pobreza multidi- 
Figura 9

\section{Incidência (H), Intensidade (A) e MPI por Unidades da Federaçáo}

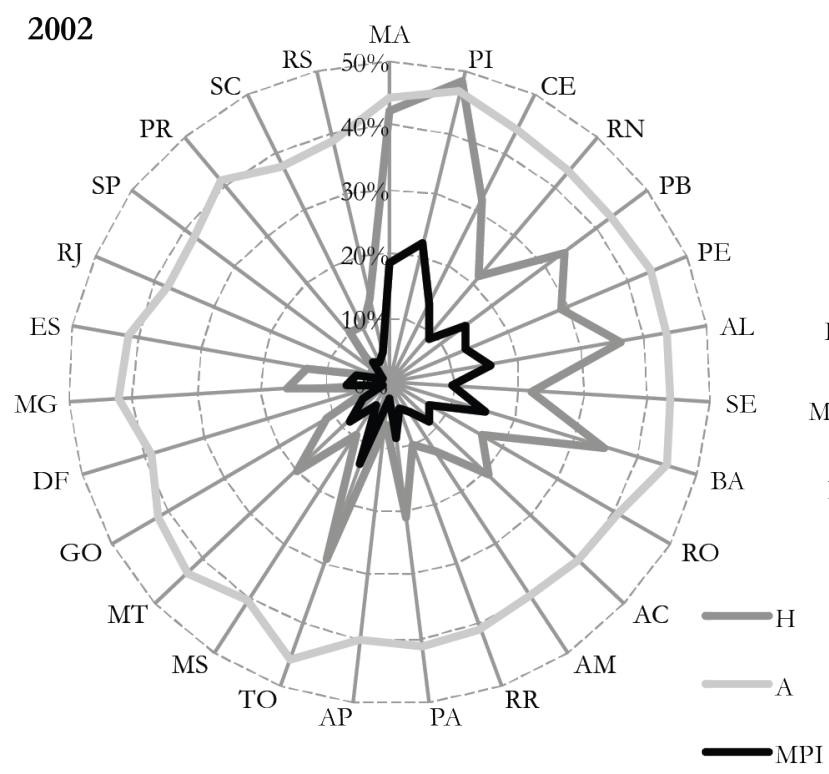

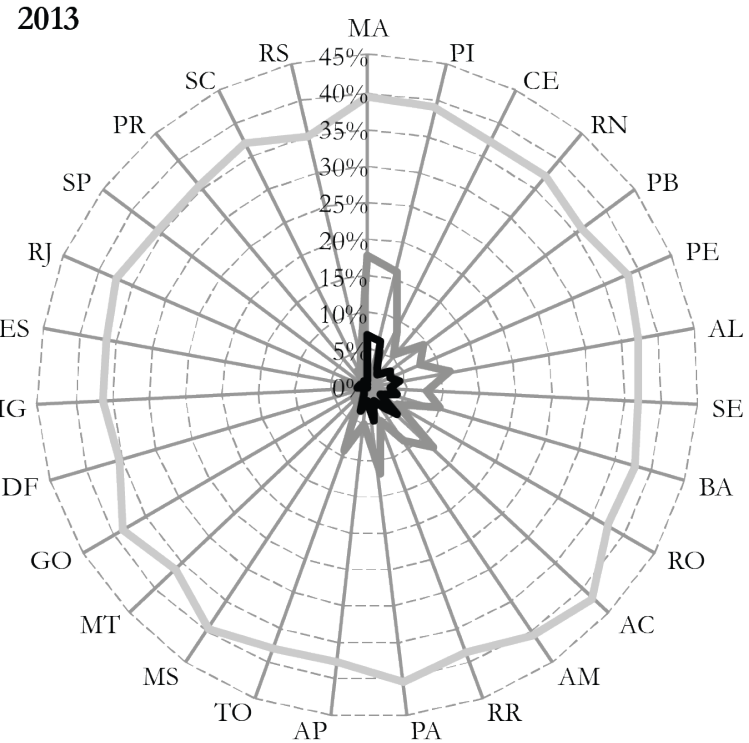

Fonte: PNADs 2002, 2007, 2012, 2013.

mensional, auxiliando na identificação das regióes e áreas sociais com maior urgência e demanda por investimento público.

Em todas as localidades é alta a contribuição relativa do indicador Anos de Escolaridade, seguido por Frequência Escolar. Entretanto, para o Nordeste e o Norte, que são as macrorregióes com pobreza multidimensional mais acentuada, é maior a contribuição relativa dos indicadores de serviços básicos de saneamento (lixo, esgoto e água). Diante disso, é coerente inferir que existe, inicialmente, uma necessidade de fortalecer as políticas sociais voltadas para a área da educação, enfatizando melhorias no desempenho escolar e na qualidade do ensino. Também, o aprofundamento de açóes de incremento do saneamento básico resultaria em grande progresso da qualidade de vida da população brasileira. Tais constataçóes podem orientar a concepção e a implementaçáo de políticas sociais a fim de que sejam mais eficazes, inovadoras e bem focalizadas, contribuindo para mudanças mais rápidas no bem- estar da população em situação de pobreza.
Desagregando o MPI em áreas urbanas e rurais é nítido o fato de a pobreza multidimensional ocorrer com maior incidência $(\mathrm{H})$ no meio rural, embora aqueles considerados pobres nessas localidades sejam acometidos por uma intensidade média de pobreza (A) ligeiramente maior que a urbana (Figura 12). Assim o MPI rural é expressivamente mais elevado que o urbano, indicando privaçóes mais acentuadas das populaçóes residentes no campo.

O quadro de pobreza multidimensional no Brasil mostra-se diferenciado em áreas urbanas e rurais. A contribuição relativa dos indicadores da dimensão Padrão de vida é bem maior nas áreas rurais (Figura 13), principalmente as variáveis de saneamento básico, revelando precariedade das condições de habitação em tais regiōes. De 2002 a 2013, ambas as áreas geográficas apresentaram progresso em todos os quesitos, embora o padrão de composição do índice pouco tenha se alterado. Os resultados para todos os indicadores são piores nas zonas rurais em relação às zonas urbanas, o que é compatível com outros indicadores e índices que reforçam a visão, já amplamente 
Figura 10

Intensidade (A) e Incidência $(\mathrm{H})$ por Unidades da Federaçáo

2002

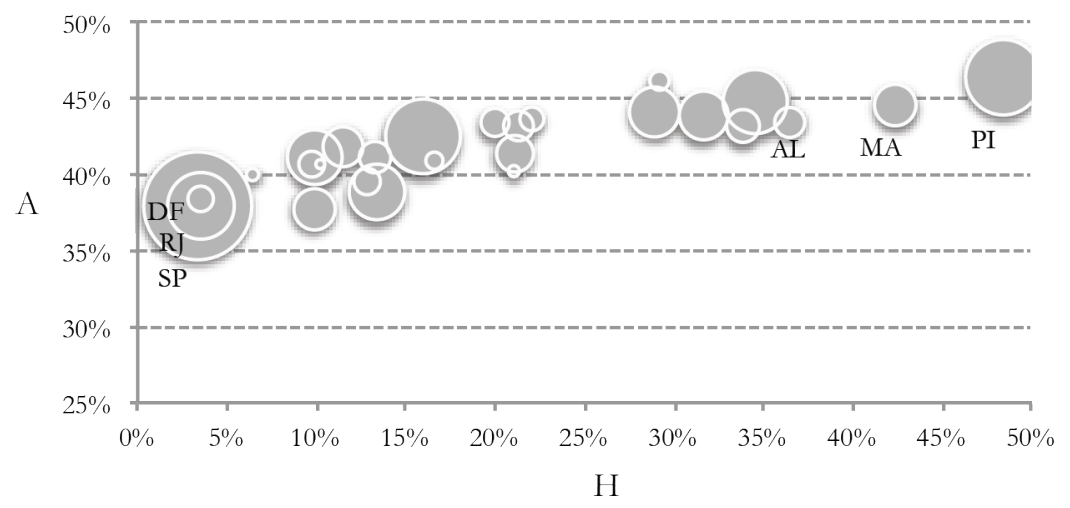

2013

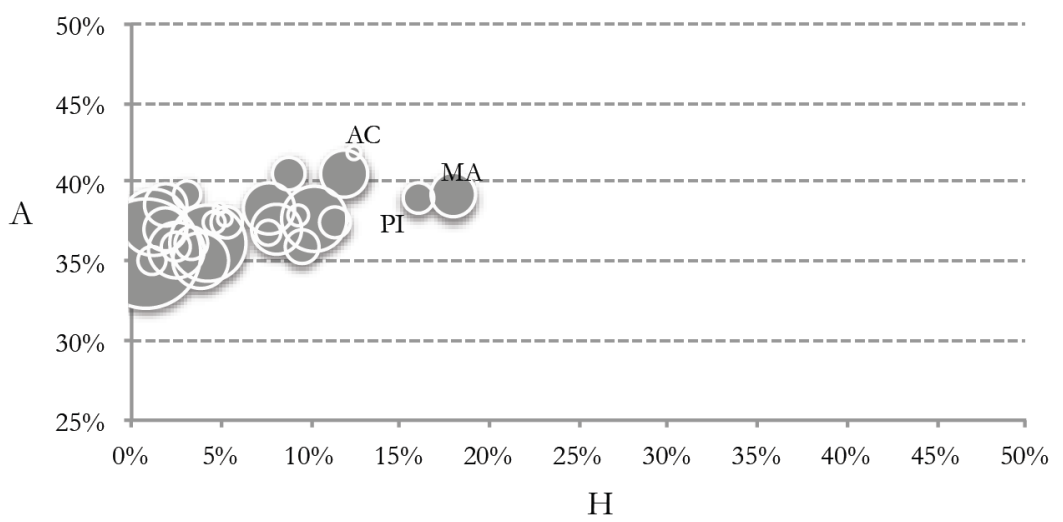

*O tamanho dos círculos é proporcional à população de cada estado.

Fonte: PNADs 2002, 2007, 2012, 2013.

Figura 11

Contribuiçáo Relativa dos Indicadores para o IPM por Macrorregióes

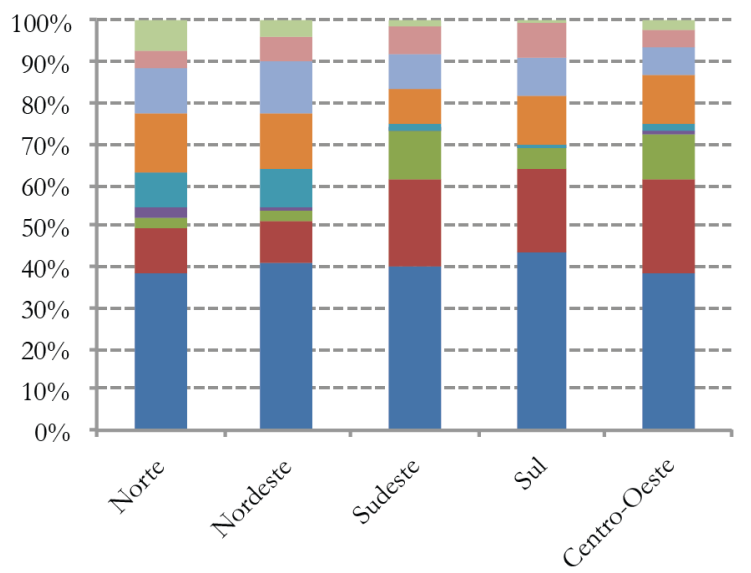

Bens Adquiridos

Combustível de Cozinha

Lixo

Esgoto

Égua

Eletricidade

Mortalidade Infantil

- Frequência Escolar

- Anos de Escolaridade

Fonte: PNADs 2002, 2007, 2012, 2013. 
Figura 12

Incidência (H), Intensidade (A) e IPM por Áreas Urbanas e Rurais

Urbana

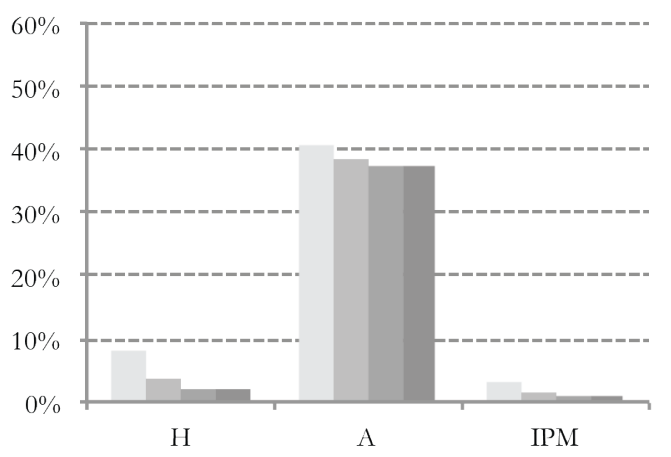

Rural

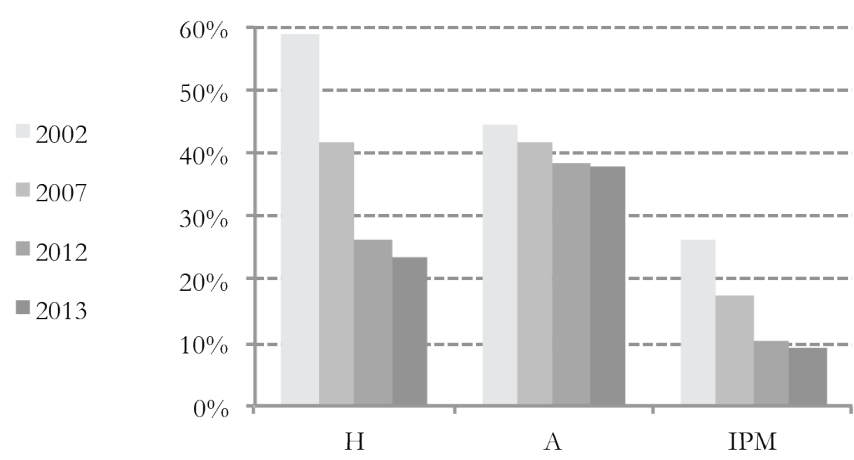

Fonte: PNADs 2002, 2007, 2012, 2013.

Figura 13

\section{Contribuição Relativa dos Indicadores para o IPM por Áreas Urbanas e Rurais}

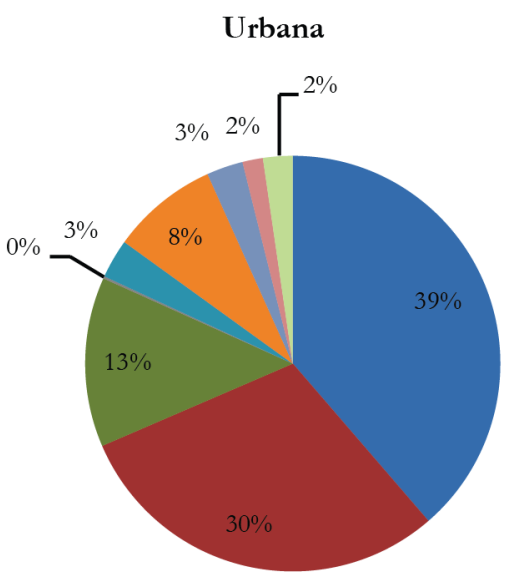

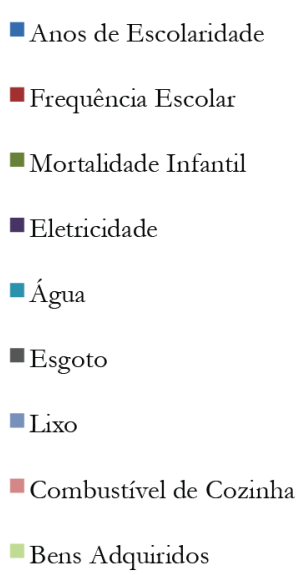

Rural

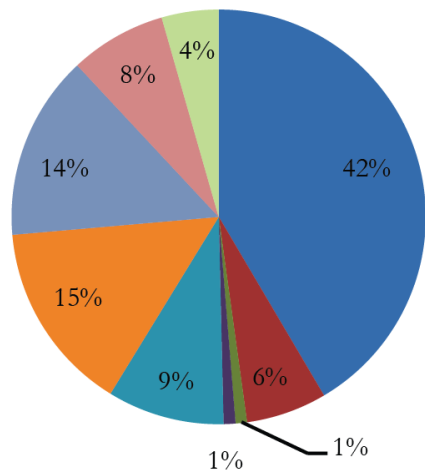

Fonte: PNADs 2002, 2007, 2012, 2013.

reconhecida, de que o fortalecimento das políticas de governo no meio rural é fundamental para o combate à pobreza.

Um exercício importante e esclarecedor consiste em comparar diferentes medidas de pobreza. Assim, sob uma perspectiva comparada, analisa-se a incidência de pobreza $(\mathrm{H})$, que é um componente do IPM, e indica a proporção de pessoas multi- dimensionalmente pobres, a proporção de pessoas vivendo com menos de $\$ 1,25$ por dia (PPP), consideradas extremamente pobres, e a proporção de pessoas vivendo com menos de $\$ 2$ por dia (PPP), consideradas pobres (Figura 14).

Nota-se que o IPM se assemelha mais à linha de pobreza monetária que denota os extremamente pobres $(\$ 1,25 /$ dia $)$ tanto em termos de nível quanto 


\section{Figura 14}

\section{Comparaçáo de Diferentes Medidas de Pobreza no Brasil}

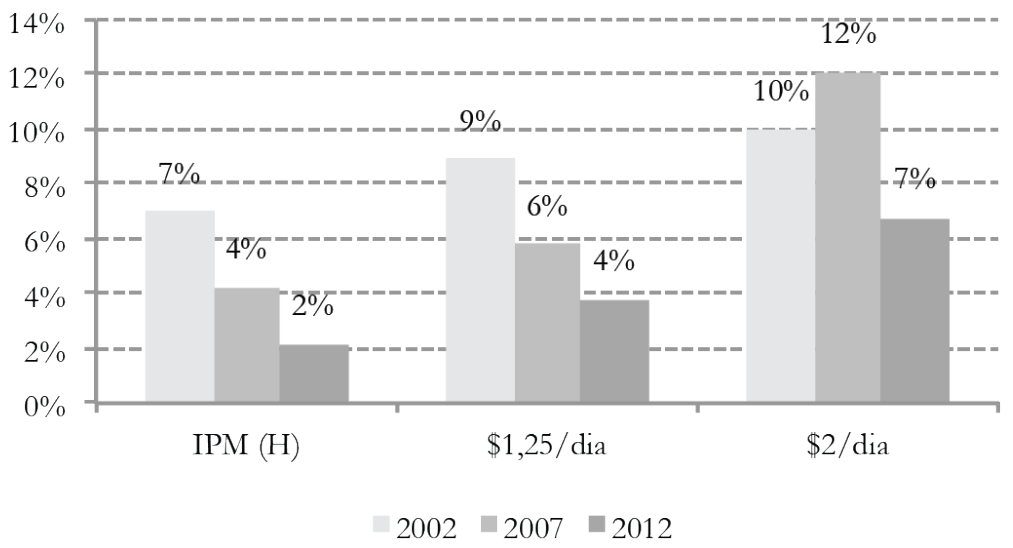

Fonte: PNADs 2002, 2007, 2012, 2013 (H) e Banco Mundial.

de tendência, reforçando sua propensão para a identificação das privações básicas (pobreza extrema) da população.

A despeito da semelhança entre as mensurações monetárias e a multidimensional, é fundamental destacar que a perspectiva multidimensional apresenta maior amplitude conceitual ao incorporar outras dimensôes e indicadores explicativos da pobreza, que náo contemplados pela visão unidimensional, restrita à questão de renda. Ou seja, a saúde, a educação e o padrão de vida, componentes estratégicos da concepção da pobreza multidimensional, agregam novos juízos e valores à questão da pobreza e contribui para uma melhor identificação das múltiplas áreas que demandam um investimento mais focalizado em termos de políticas sociais por parte do poder público.

Cabe ressaltar que resultados mais recentes de mensuração da extrema pobreza pelo critério monetário vêm indicando uma quebra da tendência de redução observada no período de 2003 a 2012 , que registrou uma queda de $7,58 \%$ para $3,63 \%$, e a partir de 2013 houve um crescimento para 4,03\% (Ipea, 2015). Com o agravamento da crise a partir do final de 2014, por meio de um intenso processo de desaceleração do cres- cimento econômico com impactos negativos na geração de emprego e na renda do trabalho associados a um quadro inflacionário, observa-se uma tendência de aumento da extrema pobreza no país mesmo com os efeitos minimizadores dos recentes aumentos de valor dos benefícios do programa Bolsa Família.

\section{Consideraçóes finais}

Por que os governos deveriam usar a mensuração da pobreza multidimensional? Do nosso ponto de vista, a adoção de uma análise multidimensional da pobreza é benéfica por contribuir para uma melhor condução de políticas sociais voltadas para a população mais pobre, considerando outras dimensóes e indicadores para além da renda. A identificação de cada dimensão e cada indicador de privação pode auxiliar o governo na formulação de políticas sociais com maior grau de resolução dos problemas identificados. Isso posto, a análise multidimensional da pobreza realizada para o Brasil é uma importante ferramenta para a orientação da concepção e da implementação de políticas sociais que possam alcançar resultados mais eficazes. Como resultado de uma melhor compreensão da natureza multi- 
dimensional da pobreza e da posterior identificaçáo dos territórios particularmente vulneráveis, o governo poderia desenvolver políticas sociais com uma boa performance em termos de custo/benefício e maximização de resultados.

Contudo, os resultados aqui apresentados requerem uma análise mais acurada, na medida em que induzem uma nova agenda na área de análise da pobreza para o país. Nesse sentido, o debate público (participação social) sobre a escolha de dimensões e indicadores para mensurar os componentes da pobreza multidimensional seria estratégico para uma maior assertividade das políticas sociais e para uma maior resiliência da população/beneficiários a perdas nos efeitos das estratégias propostas de superação da extrema pobreza. A partir dessa participação social, em um amplo escrutínio de juízos e valores em relação à concepção da pobreza multidimensional e de suas estratégias de superação, seria viabilizado uma compreensão mais clara dos seus determinantes, possibilitando uma mensuração mais condizente com a realidade social.

Ademais, este trabalho evoca uma nova agenda para o Brasil no aprofundamento das análises sobre a pobreza multidimensional, com personalização das dimensóes e dos indicadores componentes para uma melhor adequação de diagnósticos com maior grau de desagregação, bem como para uma orientação das estratégias das políticas sociais voltadas para uma atuação em macros/micros territórios mais vulneráveis. Nessa perspectiva, a nova agenda na área aponta para a modelagem e a adoção do IPM mais acurado e calibrado em níveis nacional e subnacional para contribuir com a maior resolutividade das políticas sociais em curso e vindouras. Assim, é recomendável um monitoramento sistemático da extrema pobreza no Brasil com uso da metodologia do IPM em função dos efeitos indesejáveis da atual crise econômica com consequente constrangimento dos investimentos públicos em políticas sociais, bem como para a identificação dos grupos sociais mais vulneráveis - como as famílias monoparentais femininas, a população rural, as comunidades quilombolas e indígenas, entre outros e para a implementação de políticas sociais targets e mais efetivas rumo à meta de uma redução sustentável da pobreza em todo o território nacional.

\section{Notas}

1 Na década de 1990 começaram a ser implantados no Brasil programas de transferência de renda com o intuito de combater a pobreza extrema e o trabalho infantil. Em 1996, o primeiro programa, condicionado a açóes socioeducativas, já estava disseminado por todo o país. Foram criados, entre 2000 e 2001, os programas Vale Gás, Bolsa Escola e Bolsa Alimentaçáo, de modo a ampliar o acesso à energia elétrica, promover uma melhoria na situação educacional do país e também nas condiçôes de saúde de gestantes e crianças de famílias de baixa renda. Três anos depois, esses programas foram unificados no programa Bolsa Família, de forma a eliminar sobreposiçóes e ineficiências. No ano de 2011, incorporando o Bolsa Família, foi lançado o plano Brasil sem Miséria com o objetivo de erradicar a extrema pobreza no país por meio da garantia de renda, inclusão produtiva e acesso aos serviços públicos. Do ponto de vista da renda, observou-se o fim da miséria entre as famílias do programa. Ver o site http://www.mds.gov.br/falemds/perguntas-frequentes/ superacao-da-extrema-pobreza $\% 20$.

2 A metodologia para mensuração da pobreza multidimensional analisa duas dimensóes distintas da pobreza: a incidência e a intensidade. A incidência abrange uma perspectiva aguda da pobreza multidimensional, indicando a proporçáo (quantitativo) de pobres em relação ao total da populaçáo, o que revela o número (\%) de indivíduos pobres segundo múltiplas dimensôes/indicadores. Por sua vez, a intensidade é uma medida para uma melhor caracterização da pobreza crônica, já que aponta a média de privaçóes compartilhadas entre os indivíduos multidimensionalmente pobres, indicando o seu grau de severidade. Ou seja, reflete a extensão/amplitude das privaçôes simultâneas que as pessoas multidimensionalmente pobres vivenciam.

3 Para o detalhamento das dimensóes e dos indicadores componentes da definição de pobreza multidimensional na América Latina, ver http://repositorio. cepal.org/bitstream/handle/11362/1252/S2013870_ pt.pdf?sequence $=1$. Como exemplo da definiçấo do limiar de privaçáo/carência adotada pela Cepal ilustramos com o indicador de não alcance de uma escolaridade mínima, identificado pelo domicilio em que nenhuma pessoa de 20 anos ou mais alcançou um nível mínimo de escolaridade: a) pessoas de 20 a 59 anos que não concluíram o ensino fundamental e b) pessoas de 60 anos ou mais que não concluíram o ensino primário.

4 O índice de Gini varia de 0 a 1; quando mais próximo de 0 indica uma reduçáo da desigualdade de renda entre a população. O Gini no Brasil conforme o Ipea, 
com base nos microdados da PNAD, da PME, do Censo/IBGE e de Langoni (1973), atingiu em 1960 o patamar de 0,535, semelhante ao de 2009 (0,539), e para 2012 é da ordem de 0,518 . Atualmente, com base nos dados da PNAD, o índice atingiu 0,490 em 2014.

5 No mesmo período, a taxa de crescimento acumulada do PIB foi de 27,7\%, indicando que, de acordo com a visão das pessoas, seus padróes de vida cresceram mais que o PIB sugere. Houve um forte descolamento entre a renda sob a perspectiva do PIB e da PNAD no período de 2003 a 2009, mas as séries parecem convergir.

6 "A inédita redução da desigualdade observada na década passada pode ser decomposta pelas diversas fontes de renda captadas pela PNAD e retrabalhadas da seguinte forma: Trabalho (58\%), Previdência (19\%), Bolsa Família (13\%), Benefício de Prestação Continuada - BPC (4\%) e Outras Rendas (6\%) como aluguéis e juros", segundo Ipea (2012).

7 As Seçôes "Indicadores sociais no Brasil e na América Latina" e "O corte da linha da pobreza" foram traduzidas e extraídas do site http://www.ophi.org. uk/wp-content/uploads/MPI_2011_Methodology_ Note_4-11-2011_1500.pdf?79d835.

8 Observe que na notação dessa nota metodológica os pesos dos indicadores somam 1. Isso difere da notação utilizada em Alkire e Foster $(2007,2011)$, onde os pesos dos indicadores somam o número total de indicadores considerados, denotado $d$. Entretanto, a identificaçáo do pobre pelo IPM aqui é equivalente à do artigo original.

9 Domicílios com uma pontuação de privação entre 1/5 e 1/3 são considerados "vulneráveis" devido à sua proximidade com o corte da pobreza.

10 Ver Alkire e Foster (2011a e 2001b); Alkire, Foster, Santos e Seth (2011).

11 Metodologia de Alkire e Foster (2011a e 2011b).

12 Nota-se que a fórmula de $A$ difere do Alkire e Foster (2007, 2011), pois não contém o número de indicadores de $d$ em seu denominador. Isto porque $d$ já está incluído na pontuação de privação $c_{i}(k)$, uma vez que é uma soma ponderada das privaçóes de cada pessoa considerada pobre, onde os pesos dos indicadores somam 1.

13 A população brasileira, de acordo com o Censo Demográfico 2000, era de 169.799.170 habitantes.

14 Em novembro de 2003 foi lançado, por meio do Decreto n. 4.873 de 11 de novembro de 2003, o programa Luz para Todos, com o desafio de acabar com a exclusão do acesso à energia elétrica no país, tendo como meta a cobertura de 10 milhóes de pessoas do meio rural até o ano de 2008.

\section{BIBLIOGRAFIA}

ALKIRE, S. \& FOSTER, J. (2007), "Counting and multidimensional poverty measurement". Oxford Working Paper Series. Disponível em http://www.ophi.org.uk/wp-content/uploads/ ophi-wp7.pdf. Consultado em 10 jul. 2014. . (2009), "Counting and multidimensional poverty measurement". Working Paper, n. 32, Universidade de Oxford/Human Development Initiative (OPHI). Disponível em http:// www.ophi.org.uk/wp-content/uploads/OPHI-wp32.pdf. Consultado em 10 jul. 2014.

. (2011a), "Counting and multidimensional poverty measurement". Journal of Public Economics, 95 (7-8): 476-487.

. (2011b), "Understandings and misunderstandings of multidimensional poverty measurement". Working Paper, n. 43, Universidade de Oxford/Human Development Initiative (OPHI). Disponível em http://www3. qeh.ox.ac.uk/pdf/ophiwp/OPHIWP043.pdf, Consultado em 10 ago. 2014.

ALKIRE, S. \& SANTOS, M. E. (2010), “Acute multidimensional poverty: a new index for developing countries". Working Paper, n. 38, Universidade de Oxford/Human Development Initiative (OPHI). Disponível em www. ophi.org.uk/resources/ophi-working-papers/. Consultado em 8 jul. 2014.

ALKIRE, S.; ROCHE, J. M.; EMMA, M. S. \& SETH, S. (2011), "Multidimensional poverty index 2011: brief methodological note". Universidade de Oxford, Human Development Initiative (Ophi). Disponível em http://www. ophi.org.uk/wp-content/uploads/MPI_2011_ Methodology_Note_4-11-2011_1500.pdf. Consultado em 10 jul. 2014.

BRASIL. (2010), Sintese de indicadores sociais. Rio de Janeiro, IBGE. Disponível em www.ibge. gov.br. Consultado em 10 jul. 2014.

BRASIL - Ministério do Desenvolvimento Social e Combate à Fome (MDS). (2011), Plano Brasil sem miséria. Brasília, MDS.

CADERNOS TRAVESSIA, 3 (6) (2011). Belo Horizonte, Oficina de Travessias. Disponível em http://www.scribd.com/doc/66796279/Cader- 
no-Travessia-6. Consultado em 10 jul. 2014.

COMISSÃO Econômica para a América Latina e o Caribe - Cepal. (2013), 'Panorama social da América Latina 2013: documento informativo". Coleção Relatório Anual. Disponível em http://www.cepal.org/pt-br/ publicaciones/1252-panorama-social-america-latina-2013-documento-informativo. Consultado em 4 nov. 2014.

FOSTER, J. (2007), "A report on Mexican multidimensional poverty measurement". Working Paper, n. 40, Universidade de Oxford/ Human Development Initiative (OPHI).

FUNDAÇÃO João Pinheiro. (2009), Pesquisa de amostra domiciliar do estado de Minas Gerais. Belo Horizonte, Fundação João Pinheiro. . (2012), Perfil de Minas Gerais 2012. 15 ed. Belo Horizonte, Fundação João Pinheiro. Disponível em http://www.fjp.mg.gov.br. Consultado em 12 ago. 2014.

HUMAN Development Initiative - OPHI. (2014), "Brazil country briefing", in Oxford Poverty \& Human Development Initiative (Ophi), "Multidimensional poverty index country briefing series". Disponível em http://www.ophi.org.uk/ multidimensional-poverty-index/mpi-2014/mpi-country-briefings/. Consultado em 10 jul. 2014.

INSTITUTO Brasileiro de Geografia e Estatística - IBGE. (2014a), Pesquisas sobre população. Brasília, IBGE. Disponível em www.ibge.gov. br. Consultado em 12 ago.

. (2014b), Pesquisas nacionais de amostra domiciliar - PNADS de 2002, 2007, $2012 e$ 2013. Brasília, IBGE. Disponível em www. ibge.gov.br. Consultado em 12 ago.

INSTITUTO de Pesquisa Econômica Aplicada Ipea. (2011), Situação social nos estados: Minas Gerais. Brasília, Disoc.

. (2012), "Comunicados do Ipea n. 155 sobre a década inclusiva (2001-2011): desigualdade, pobreza e políticas de renda em 25 de setembro de 2012". Disponível em http://www. ipea.gov.br/portal/index.php?option $=\mathrm{com}_{-}$ content\&view=article\&id=15611. Consultado em 10 dez. 2014

. (2015), "Políticas sociais: acompanhamento e análises". Boletim de Politicas Sociais,
23, Rio de Janeiro, Diretoria de Estudos e Políticas Sociais.

PNUD. (1997), Relatório de Desenvolvimento Humano 1997: desenvolvimento humano para erradicar a pobreza. Nova York, PNUD.

SANTOS, M. E. \& ALKIRE, S. (2011), "Training material for producing national human development reports: the multidimensional index (IPM)". Universidade de Oxford/Human Development Initiative (OPHI). Disponível em www. ophi.org.uk/multidimensional-poverty-index/ mpi-resources/. Consultado em 4 nov. 2014.

SEN, A. (2000), Desenvolvimento como liberdade. São Paulo, Companhia das Letras. 


\section{PARA ALÉM DA RENDA: UMA ANÁLISE DA POBREZA MULTIDIMENSIONAL NO BRASIL}

\section{Murilo Fahel}

Palavras-chaves: Pobreza multidimensional; Incidência; Intensidade; Índice; Brasil.

O Índice de Pobreza Multidimensional (IPM) foi adotado pelo Programa das Naçóes Unidas para o Desenvolvimento (PNUD) e desenvolvido pela Oxford Poverty \& Human Development Initiative (OPHI) desde 2010 em consonância com o novo paradigma analítico internacional do fenômeno da pobreza. A metodologia utilizada neste estudo é baseada em Alkire e Foster (2011), que analisa a incidência e a intensidade da pobreza, ou seja, a porcentagem de indivíduos pobres e a distância média que esses indivíduos estão de uma situação de não pobreza. $\mathrm{O}$ objetivo é aplicar o IPM ao Brasil, utilizando os dados da Pesquisa Nacional por Amostra de Domicílios de 2002, 2007 , 2012 e 2013, produzida pelo IBGE. Os resultados indicam que o IPM no Brasil atinge 6,97\% (2002) e 1,95\% (2013), demonstrando que há uma tendência de redução entre os anos.

\section{BEYOND INCOME: ANALYSIS OF MULTIDIMENSIONAL POVERTY IN BRAZIL}

\section{Murilo Fahel}

Keywords: Multidimensional Poverty; Incidence; Intensity; Index; Brazil

Being developed since 2010 by the $\mathrm{Ox}$ ford Poverty \& Human Development Initiative in accordance with the new international analytical paradigm on the phenomenon of poverty, the Multidimensional Poverty Index (MPI) has been adopted by the United Nations Development Program (UNDP). The methodology used in this study is based on Alkire and Foster (2011), and analyses the incidence and intensity of poverty, i.e. the percentage of poor individuals and the average distance separating them from the situation of non-poverty. The paper's purpose is to apply the MPI to the Brazilian case, using the National Household Sample Survey produced by the IBGE in the years 2002, 2007, 2912, and 2013. The results obtained indicate that the MPI in Brazil is of $6.97 \%$ in 2002 and comes to an index of $1.93 \%$ in 2013, indicating a decreasing tendency along the period encompassed by the study.

\section{AU-DELÁ DES REVENUS : UNE ANALYSE DE LA PAUVRETÉ MULTIDIMENSIONNELLE AU BRÉSIL}

\section{Murilo Fahel}

Mots-clés: Pauvreté multidimensionnelle; Incidence ; Intensité ; Indice ; Brésil.

L'Indice de Pauvreté Multidimensionnelle (IPM) a été adopté par le Programme des Nations Unies pour le Développement (PNUD) et développé depuis 2010 par l'Oxford Poverty \& Human Development Initiative (OPHI), en consonance avec le nouveau paradigme de l'analyse internationale du phénomène de la pauvreté. La méthodologie utilisée dans cette étude est basée sur Alkire et Foster (2011), qui analysent l'incidence et l'intensité de la pauvreté, à savoir, le pourcentage de personnes pauvres et la distance moyenne de ces personnes face à un cadre de non pauvreté. Le but de cet article est d'appliquer l'IPM au Brésil en utilisant les données statistiques de l'Enquête nationale par échantillon des ménages de 2002, 2007, 2012 et 2013, produit par l'IBGE. Les résultats indiquent que l'IPM au Brésil en 2002 a atteint $6,97 \%$ (en 2002) et $1,95 \%$ (en 2013) ce qui démontre une tendance à la baisse. 